\title{
Association of ET-1 gene polymorphisms with COPD phenotypes in a Caucasian population
}

\author{
A. Kaparianos1, F. Sampsonas1, D. Lykouras1, G. Efremidis1, \\ P. Drakatos 1 , K. Karkoulias 1 , C. Gogos ${ }^{2}$, K. Spiropoulos ${ }^{1}$
}

ABSTRACT: Association of ET-1 gene polymorphisms with COPD phenotypes in a Caucasian population. A. Kaparianos, F. Sampsonas, D. Lykouras, G. Efremidis, $P$. Drakatos, K. Karkoulias, C. Gogos, K. Spiropoulos.

Background and Aim. The phenotypic expression of COPD consists of pulmonary emphysema and chronic bronchitis. An imprecise phenotypic definition may result in inconsistencies among genetic studies regarding COPD pathogenesis. Endothelin-1 gene polymorphisms have been linked to increased susceptibility of COPD development. The present study examined the involvement of +138 insA/delA and G198T ET-1 polymorphisms with emphysematous and bronchitic COPD phenotypes.

Methods. In order to narrow down the phenotypic choices to either COPD-associated pulmonary emphysema or chronic bronchitis, a DLCO $<60 \%$ predicted threshold was chosen as an indicator of severe emphysema.116 COPD smokers and 74 non-related, non-COPD smokers were evaluated.

Results. Statistical analysis showed that the $4 \mathrm{~A}$ allele of the +138insA/delA SNP and the 4A:T haplotype were associated predominantly with a chronic bronchitis phenotype, whereas the TT genotype of the G198T SNP was found to be protective from emphysema development.

Conclusions. The presence of both the $4 \mathrm{~A}$ and $\mathrm{T}$ allele seems to modify the final expression of COPD towards a chronic bronchitis phenotype, since the G:3A haplotype was associated with a predominantly emphysematous phenotype in our study.

Monaldi Arch Chest Dis 2011; 75: 2, 126-131.

Keywords: Bronchitis, COPD, Endothelin-1, Emphysema, Polymorphism.

1 Pulmonary Department, Division of Internal Medicine, University Hospital of Patras,

2 Division of Internal Medicine, University Hospital of Patras, Greece.

Drs Kaparianos \& Sampsonas contributed equally for the present manuscript.

Correspondence: Alexandros Kaparianos MD, PhD, Pulmonary Department, Division of Internal Medicine, University Hospital of Patras, 26504, Rion Patras, Greece; e-mail: pneumonas@hotmail.com

\section{Introduction}

Chronic obstructive pulmonary disease (COPD) is a worldwide leading cause of morbidity and mortality. Tobacco smoking, combined with a susceptible genetic background, is the main environmental risk factor for COPD development. In an attempt to understand the role of responsible genetic factors, a plethora of gene polymorphisms have been evaluated, but many of the associations found were controversial since they have not been replicated in different populations [1-3].

COPD is a heterogeneous condition consisted of two phenotypes: pulmonary emphysema and chronic bronchitis that are expressed in different levels among patients $[4,5]$. Inconsistencies in genetic studies could be attributed to an inadequate phenotypic definition. Emphysematous phenotype can be identified and its severity graded using pathological and radiological terms, whereas the diagnosis of bronchitis is mainly based on a spectrum of clinical symptoms [5]. Phenotypic characterisation of COPD patients, based on High Resolution Computed To- mography (HRCT) scans and its association to traditional techniques of emphysema evaluation that involves measurement of diffusion lung capacity, revealed that the diffusing capacity of the lung for carbon monoxide (DLCO) value that corresponds to the presence of extended emphysema (as evidenced by HRCT scans) is about $60 \%$ or less $[6,7]$.

There is growing evidence that the ET- 1 system is involved in the regulation of apoptosis [8]. A model of COPD pathogenesis and pulmonary hypertension development suggested that apoptosis of alveolar cells followed by the failure of the vascular and epithelial tissue to properly repair itself may be the cause of emphysema. Smoke exposure provokes a number of harmful vascular effects, as it increases the expression of vasoconstrictor and mitogenic factors, such as endothelin-1 (ET-1) [4]. The autocrine actions of ET-1 (pro-inflammatory, vasoconstrictor and mitogenic) may be involved at an early stage in lung remodeling due to smoking, and also could contribute to disease severity and pulmonary hypertension [4], all of which are major characteristics of the chronic bronchitis phenotype of COPD. 
The human ET-1 gene is located on chromosome $6 \mathrm{p}$ and consists of 5 short exons and 4 introns. Transcription of its mRNA forms a precursor molecule, the preproendothelin-1, which is subsequently hydrolysed to form the active 21 amino acid ET-1 peptide. Single nucleotide polymorphisms (SNPs) of the ET-1 gene have been associated with variations in the serum levels of ET1 activity $[9,10]$. An adenine insertion SNP is located 138 bp downstream of the transcription start site in the 5'-UTR (Untranslated Region), in exon $1(+138$ 3A/4A) [9]. Recent studies have shown that this insertion accounted for elevated ET-1 levels, probably due to increased mRNA stability. Preproendothelin-1 mRNA can form different stem-loops of 5'-UTR transcripts and the adenine insertion changes the free energy, number and secondary structure of its stem-loops thereby altering its stability [9]. Another SNP that involves transversion of guanine $(\mathrm{G})$ to thymine $(\mathrm{T})$ in codon 198 (G198T) leads to substitution of lysine residue by asparagine (Lys198Asn) has also been associated with variations in ET-1 serum levels [10].

Recent studies conducted by the authors revealed a plausible association of the abovementioned SNPs with COPD development, its severity and with the rate of decline of lung function [11, 12]. Nevertheless, the involvement of these SNPs in COPD phenotypes (bronchitis, emphysema) has never been evaluated. Taking into account the plausible role of ET-1 in the maintenance and augmentation of inflammation in the lung of COPD patients, polymorphisms of the ET-1 could also modulate the risk of chronic bronchitis and emphysema development $[13,14]$. To test this hypothesis, we conducted a case control study to examine their association with impairment in DLCO, a functional abnormality known to be associated with pulmonary emphysema [15].

To the best of our knowledge, no study has ever evaluated the role of the ET-1 gene complex in the pathophysiology of pulmonary emphysema and chronic bronchitis.

\section{Materials and methods}

\section{Subjects}

The study population consisted of 190 subjects, including 116 COPD smokers that were recruited from the outpatient Pulmonary Department of Patras University Hospital and 74 non-COPD smokers defined as controls, randomly selected from the general population (visitors of the hospital for a health check-up and community volunteers). All participants were current or ex-smokers with a history of smoking at least 20 pack/years and were subjected to spirometry, including a bronchodilator test. A computerised system was used (Pulmolab 435 Morgan Data Acquisition System 401, USA) and the pulmonary function tests were carried out by the same technician according to guidelines [16]. The cumulative cigarette dose (pack/year) was calculated using the fol- lowing formula: pack-year $=($ packs per day $) \mathrm{x}$ (years of smoking).

Regarding the Forced Expiratory Volume in one second $\left(\mathrm{FEV}_{1}\right)$, the higher values in two technically satisfactory tracings were used. Additionally, $\mathrm{FEV}_{1}$ reversibility was judged after inhalation of $200 \mu \mathrm{g}$ salbutamol. Patients with a positive bronchodilator response $(>12 \%$ and $200 \mathrm{ml}$ increase in $\mathrm{FEV}_{1}$ ) were excluded from the study. Subjects were then staged according to the criteria proposed by the Global Initiative for Chronic Obstructive Pulmonary Disease [GOLD]. DLCO was determined using the single-breath method and its value was corrected for hemoglobin content [16, 17]. Non-COPD smoking controls had normal spirometric and DLCO values (DLCO>75\%) while COPD patients has a FEV 1 to FVC ratio lower than $0.7\left(\mathrm{FEV}_{1} / \mathrm{FVC}<0.7\right)$. A DLCO value over $60 \%$ among COPD patients was used to signify a predominantly chronic bronchitis phenotype while a DLCO value lower than $60 \%$ a predominantly emphysematous phenotype. All bronchitis patients fulfilled the clinical criteria for bronchitis: persistent cough that produces sputum and mucus, for at least three months over two consecutive years. This was done through the use of appropriate questionnaires as part of their interview at the time of their enrollment.

All subjects had no other major co-morbidities such as heart failure, renal dysfunction, cirrhosis, cancer or severe hypertension. Patients with poorly reversible airflow limitation associated with bronchiectasis, cystic fibrosis and fibrosis due to tuberculosis were excluded.

The study was approved by the University of Patras Ethics Committee and the Scientific Committee of the University Hospital of Patras, and all subjects signed a consent form. The study conforms to the relevant ethical guidelines for human and animal research.

\section{Blood collection and genotyping}

DNA was isolated from $3 \mathrm{ml}$ of whole blood, using QIAamp DNA blood mini kit (QIAGEN). The ET1 gene polymorphisms Lys198Asn (C198 GT) in exon 5 and the $+1383 \mathrm{~A} / 4 \mathrm{~A}$ in the 5 'untranslated region were genotyped in 190 subjects. Genotyping was performed using real time PCR and the MX3000p sequencer (Stratagene, La Jolla, CA, USA). The primers and MGB Taqman probes used for the Lys198Asn (C198 GT) polymorphism were as previously reported [11]. For the +138 3A/4A polymorphism the primers 5'- TTC TCT CCT GGC AGG -3' and 5'- ATC TCA AAG CGA TCC TTC -3 ' were used in conjunction with the LNA (Locked Nucleic Acid) Taqman probes 5'(6-Fam) AG+TGCC+C+T+T+TAACGG (BHQ1)3' (for 3A allele) and 5'-(Hex) AGT GCC $+\mathrm{C}+\mathrm{T}+\mathrm{T}+\mathrm{T}+\mathrm{TAA}+\mathrm{CG}+\mathrm{GG}$ (BHQ1)-3' (for 4A), where a "+" before the base indicates an LNA base. Primers were synthesised by Metabion International (Martinsried, Germany), MGB probes by Applied Biosystems (Foster City, CA, USA) and LNA probes by Sigma-Proligo (The Woodlands, 
TX, USA). Reactions were performed using Brilliant QPCR Master Mix (Stratagene).

\section{Statistical analysis and methodology}

The normality of variables studied was tested using the Kolmogorov-Smirnov test. Comparisons of demographic data between groups was performed with the Chi-square $\left(\chi^{2}\right)$ analysis or unpaired t-test, as appropriate. To distinguish between chronic bronchitis and emphysematous patients a DLCO value $<60 \%$ pred. $[8,9]$ was used as a marker for severe pulmonary emphysema, as set out above. Correlations between spirometric values, DLCO and patient genotypes were tested with one way ANOVA. For multiple comparisons, the ANOVA tests were followed by a post hoc Bonferroni analysis. P-values lower than 0.05 were considered significant. Statistical analysis was performed using SPSS statistical package (SPSS, Release 14.0.1, Chicago, IL, USA). Haplotypic analysis was performed using the FAMHAP software program, based on the Monte-Carlo simulations. The haplotypic frequencies computed by the program are maximum-likelihood estimates
(MLEs), obtained with the expectation-maximisation (EM) algorithm.

\section{Results}

\section{Characterisation of subjects}

Demographic data among COPD patients (emphysematous and non-emphysematous) and controls is displayed in table 1. DLCO and $\mathrm{FEV}_{1}$ values were significantly decreased in the emphysematous and chronic bronchitis COPD groups compared to controls $(p<0.001)$. The difference in $\mathrm{FEV}_{1}$ values between emphysematous patients (DLCO $<60 \%, \mathrm{n}=44)$ and patients with bronchitis (DLCO $>60, n=72$ ) was not statistically significant. The group of COPD patients consisted of $105 \mathrm{ac}-$ tive and 11 ex-smokers, whereas the control group of 67 active and 7 ex-smokers. Genotypes of both the control and COPD group were found by Pearson's goodness-of-fit chi-square test to be in Hardy-Weinberg equilibrium ( $>0.05$ ).

Statistical analysis revealed that the distribution of genotypes was remarkably different among COPD phenotypes (Global $\mathrm{p}<0.01, \chi^{2}=10.553$, table 2 ) and

Table 1. - Baseline demographic and spirometric characteristics of COPD patients and non-COPD smoking controls

\begin{tabular}{lcccc}
\hline & $\begin{array}{c}\text { COPD patients emphysema } \\
(\mathbf{n}=\mathbf{4 4})\end{array}$ & $\begin{array}{c}\text { COPD patients bronchitis } \\
(\mathbf{n}=\mathbf{7 2})\end{array}$ & $\begin{array}{c}\text { Non-COPD smoking } \\
\text { controls }(\mathbf{n}=\mathbf{7 4})\end{array}$ & p VALUE \\
\hline Smoking (pack years) & $63.8( \pm 29.3)$ & $63.2( \pm 27.97)$ & $55.2( \pm 27,2)$ & $\mathrm{NS}$ \\
Age (years) & $61.45( \pm 10.45)$ & $62.3( \pm 11.1)$ & $58.3( \pm 10)$ & $\mathrm{NS}$ \\
SEX (M/F) & $38 / 6$ & $62 / 10$ & $68 / 6$ & $\mathrm{NS}$ \\
DLCO (\%predicted) & $42.6( \pm 14)$ & $79.17( \pm 11.64)$ & $105.2( \pm 22.7)$ & $<0.001$ \\
FEV $(\%$ predicted) & $53.4( \pm 15.94)$ & $57.1( \pm 15.9)$ & $99.66( \pm 11.47)$ & $<0.001$ \\
Current/ex-smokers & $40 / 4$ & $65 / 7$ & $67 / 7$ & $\mathrm{NS}$ \\
\hline
\end{tabular}

I: Post bronchodilation $\mathrm{FEV}_{1}$; NS = non significant, M: Male, F: Female, DLCO: diffusing capacity of carbon monoxide.

Table 2. - Genotype distribution of the +138 insA/delA and G198T genotypes in the COPD patient group

\begin{tabular}{|c|c|c|c|c|c|c|}
\hline \multirow{3}{*}{$\begin{array}{l}\text { Polymorphism } \\
+\mathbf{1 3 8 i n s A / d e l A}\end{array}$} & \multicolumn{2}{|c|}{ Genotype distribution } & & \multirow{3}{*}{$\left(\chi^{2}\right)$} & \multirow{3}{*}{ OR } & \multirow{3}{*}{$95 \% \mathrm{CI}$} \\
\hline & $\begin{array}{c}\text { COPD } \\
\text { patients-bronchitis } \\
\text { DLCO }>60\end{array}$ & $\begin{array}{c}\text { COPD } \\
\text { patients-emphysema } \\
\text { DLCO }<60\end{array}$ & \multirow[t]{2}{*}{$\mathrm{p}$ value } & & & \\
\hline & $\mathrm{n}(\%)$ & $\mathrm{n}(\%)$ & & & & \\
\hline 3A3A & $62(86)$ & $24(55)$ & \multirow{3}{*}{$\mathrm{p}<0.001$} & \multirow{3}{*}{ (10.553) } & \multirow{3}{*}{3.238} & \multirow{3}{*}{$1.52-6.9$} \\
\hline $3 \mathrm{A4A}$ & $10(14)$ & $18(41)$ & & & & \\
\hline $4 \mathrm{~A} 4 \mathrm{~A}$ & $0(0)$ & $2(4)$ & & & & \\
\hline \multicolumn{7}{|l|}{$\begin{array}{l}\text { Polymorphism } \\
\text { G198T }\end{array}$} \\
\hline GG & $46(64)$ & $26(59)$ & \multirow{3}{*}{$\mathrm{p}=0.37$} & \multirow{3}{*}{$(0.267)$} & \multirow{3}{*}{0.925} & \multirow{3}{*}{$0.685-1.25$} \\
\hline GT & $24(33)$ & $18(41)$ & & & & \\
\hline TT & $2(3)$ & $0(0)$ & & & & \\
\hline
\end{tabular}

OR $=$ Odds Ratio, $95 \% \mathrm{CI}=$ Confidence interval. 


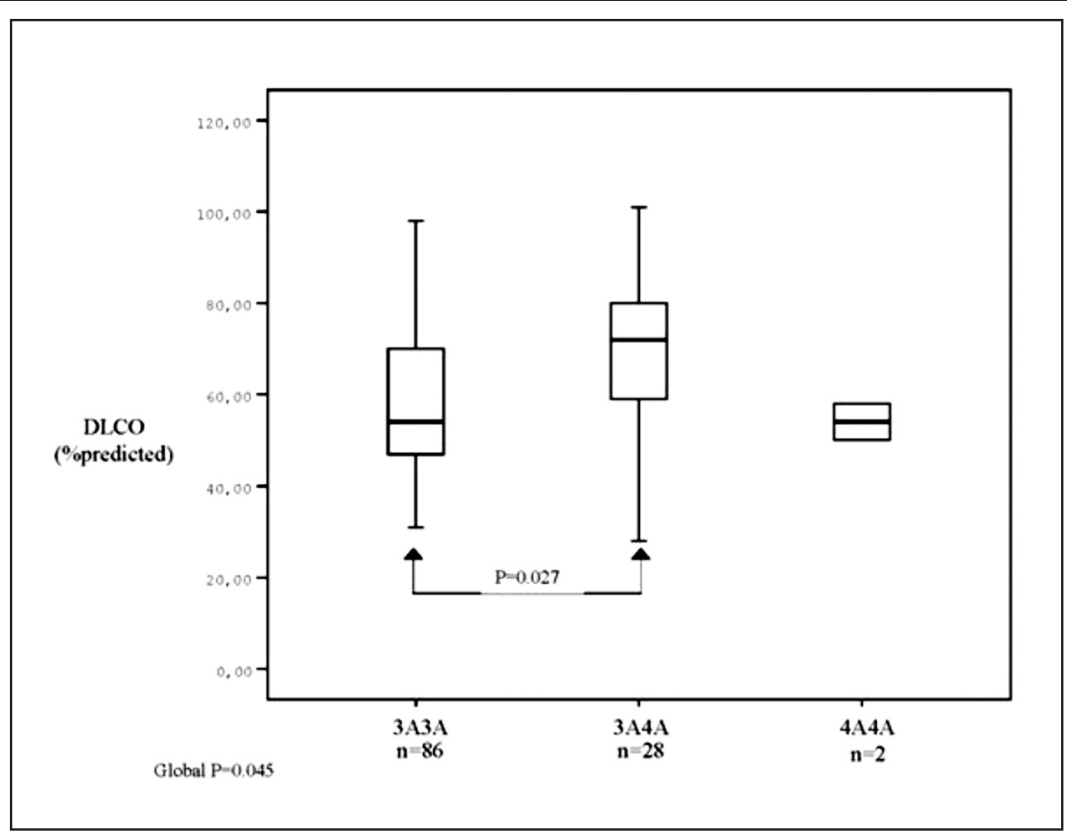

Fig. 1. - DLCO values and their association with $3 \mathrm{~A} 3 \mathrm{~A}$ and $3 \mathrm{~A} 3 \mathrm{~A} / 4 \mathrm{~A} 4 \mathrm{~A}$ genotypes in the COPD patient group.

that the 3A4A genotype was more common in bronchitis group compared to emphysema group $(\mathrm{OR}=3.238,95 \% \mathrm{CI}=1.52-6.9$, table 2$)$. Carriers of $3 \mathrm{~A} 4 \mathrm{~A}$ genotype $(\mathrm{n}=28)$ had significantly better DLCO values compared to those carrying the 3 A3A genotype $(n=86)(p=0.027$, figure 1$)$. Statistical analysis showed that the $4 \mathrm{~A}$ allele of the +138 insA/delA SNP and the 4A:T haplotype were associated predominantly with a chronic bronchitis phenotype, whereas the TT genotype of the G198T SNP was found to be protective from emphysema development (tables 3 and 4). The genotypic distribution of the +138 ins/delA SNP is different in patients with bronchitis, compared to non-COPD controls (Global $\mathrm{p}<0.01, \chi^{2}=24.17$, table 3 ). Therefore, carriers of at least on $4 \mathrm{~A}$ allele are in increased risk of bronchitis development $(\mathrm{OR}=1.73$, 95\% CI=1.362-2.197, table 3).

Haplotypic distribution of the aforementioned genotypes among COPD subjects is exhibited in table 5. The G:3A haplotype was more common in the emphysematous patient group $(\mathrm{OR}=1.608$, $95 \% \mathrm{CI}=0.9197-2.8127)$, whereas the $\mathrm{G}: 4 \mathrm{~A}$ was more common in the chronic bronchitis COPD group $(\mathrm{OR}=1.471$, $95 \% \mathrm{CI}=0.8184-2.6376$, table 3$)$. Moreover the 4A:T haplotype was more common in the chronic bronchitis COPD group (OR: 2.999, 95\%CI: 0.4014-22.4091). The difference in the distribution of haplotypes among the two COPD groups did not reach statistical significance $(p=0.067)$.

\section{Discussion}

Phenotypic choice and biological reasonability of candidate genes constitute a fundamental knowledge for genetic investigations on a complex condition as COPD clearly is [18]. Many previously published papers, dealing with variety genes in COPD, have used $\mathrm{FEV}_{1}$ as an objective parameter to define the phenotype of COPD [11, 19-20]. Although $\mathrm{FEV}_{1}$ represents a reliable tool for COPD staging and follow-up [21], is not useful in the context of emphysema recognition. Additionally, the severity of emphysema varies widely, even in the same COPD stage [22]. Thus, $\mathrm{FEV}_{1}$ has its limitations in the definition of these patients affected by this widely heterogeneous condition [23]. COPD-associated chronic airflow limitation is caused by both small airway disease and emphysema, the relative contribution of which varies from person to person.

In an attempt to narrow down the phenotypic choices to COPD-associated pulmonary emphysema and chronic bronchitis, a severe reduction of DLCO $(<60 \%$ predicted) was used as an inclusion criterion for severe emphysema. $\mathrm{FEV}_{1} \%$ pred. is weakly related to the extent of emphysema $[8,15$, 22], suggesting that airflow obstruction in severe COPD is not totally accounted for by the extent of emphysema. On the other hand, DLCO is influenced by parenchymal destruction involving respiratory bronchioles, alveoli and the pulmonary capillary system, and is reduced in patients with emphysema because of the loss of alveolo-capillary

Table 3. - Distribution of the +138 insA/delA SNP between non-COPD smokers and non-emphysematous COPD smokers

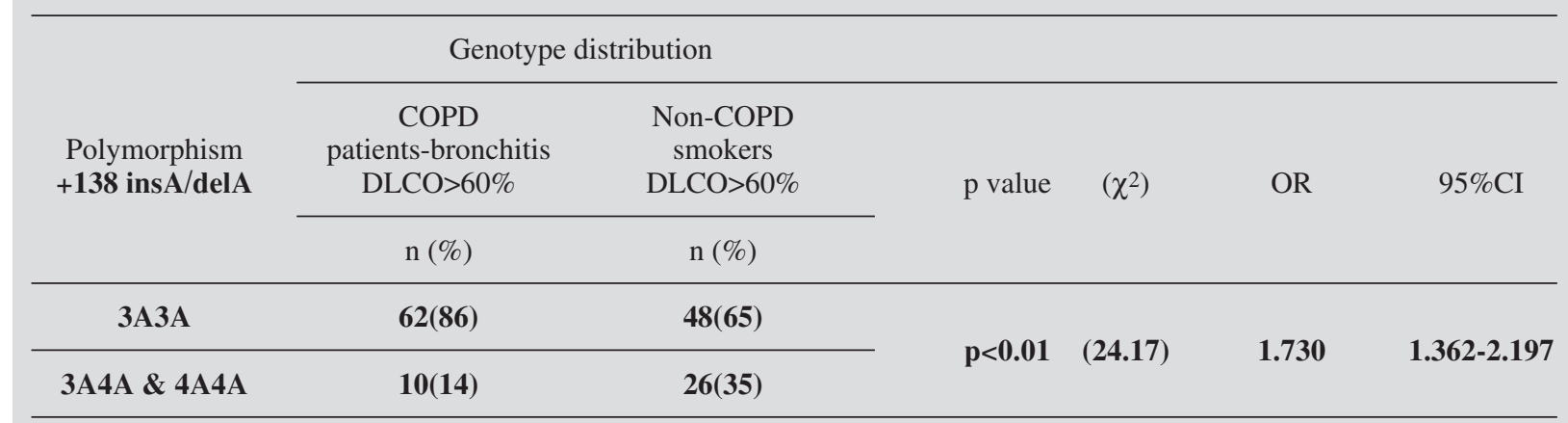

$\mathrm{OR}=$ Odds Ratio, $95 \% \mathrm{CI}=$ Confidence interval. 
Table 4. - Genotype distribution of the G198T SNP between emphysematous COPD patient group and non-COPD smokers

\begin{tabular}{cccc}
\hline & \multicolumn{2}{c}{ Genotype distribution } & \\
\cline { 2 - 3 } $\begin{array}{c}\text { Polymorphism } \\
\text { G198T }\end{array}$ & $\begin{array}{c}\text { Non-COPD } \\
\text { smokers } \\
\text { DLCO }>75 \%\end{array}$ & $\begin{array}{c}\text { Patients-emphysema } \\
\text { DLCO<60\% }\end{array}$ & p value $\quad\left(\chi^{2}\right)$ \\
\cline { 2 - 3 } GG & $\mathrm{n}(\%)$ & $\mathrm{n}(\%)$ & \\
\hline GT & $22(58)$ & $\mathbf{p = 0 . 0 4 1} \quad$ (6.37) \\
\hline TT & $9(12)$ & $18(41)$ & \\
\hline
\end{tabular}

OR $=$ Odds Ratio, $95 \% \mathrm{CI}=$ Confidence interval

Table 5. - Haplotypic distribution between emphysematous and non-emphysematous COPD phenotypes

\begin{tabular}{ccccc}
\hline Haplotypes & Emphysematous group & Non-emphysematous group & OR & 95\%CI \\
\hline $3 \mathrm{~A}: \mathrm{G}$ & $41.8 \%$ & $53.6 \%$ & 1.608 & $0.9197-2.8127$ \\
\hline $4 \mathrm{~A}: \mathrm{T}$ & $3.8 \%$ & $1.3 \%$ & 2.999 & $0.4014-22.4091$ \\
\hline $3 \mathrm{~A}: \mathrm{T}$ & $15.3 \%$ & $14.6 \%$ & 1.056 & $0.48562-2.2992$ \\
\hline $4 \mathrm{~A}: \mathrm{G}$ & $39.2 \%$ & $30.5 \%$ & 1.471 & $0.8184-2.6376$ \\
\hline Total & $\mathbf{1 0 0 \%}$ & $\mathbf{1 0 0 \%}$ & & \\
\hline
\end{tabular}

OR = Odds Ratio, $95 \% \mathrm{CI}=$ Confidence interval.

surface. Reduction of DLCO correlates strongly with the severity of emphysema, as assessed by high-resolution computed tomography analysis [7$9,24,25]$.

The inflammatory response of COPD affects in small airways and alveoli and is characterised by its failure to abate when cigarette smoking is withdrawn and becomes independent of the inciting mechanism $[26,27]$. It has been reported that ET-1 is implicated in COPD pathogenesis via its involvement in the inflammatory cycle and this is supported by studies that show increased levels of ET-1 in samples of bronchoalveolar lavage fluid and sputum of COPD patients that increase further during exacerbations of the disease $[13,14]$. ET-1 preserves inflammation in the respiratory mucosa independently of the initial inflammatory stimulus, therefore establishing an autocrine/paracrine loop.

The role of the ET-1 gene SNPs in COPD phenotypes (emphysema and bronchitis) has never been studied. We showed that the $4 \mathrm{~A}$ allele seems to be associated to the chronic bronchitis phenotype of COPD, probably due to the increased ET-1 levels in the airway wall. Consequently, the aforementioned cycle of inflammation could be easily established and enhanced, leading to chronic mucous hypersecretion, bronchoconstriction and airway remodeling, major characteristics of chronic bronchitis. Haplotypic analysis also revealed that the 4A:T haplotype is associated with the chronic bronchitis phenotype. The presence of both the 4A and $\mathrm{T}$ allele seems to modify the final expression of COPD towards a chronic bronchitis phenotype, since the G:3A haplotype was associated with a predominantly emphysematous phenotype in our study.

Our results indicate that $+1383 \mathrm{~A} / 4 \mathrm{~A}$ and G198T SNPs of ET-1 gene are possibly involved not only in COPD pathogenesis but also modulate the phenotypic expression of this disease, namely emphysema and chronic bronchitis. However, studies that include a greater number of subjects and make use of HRCT scores apart from DLCO to delineate emphysema and are needed to verify our findings.

\section{References}

1. Sampsonas F, Karkoulias K, Kaparianos A, Spiropoulos K. Genetics of Chronic Obstructive Pulmonary Disease, beyond $\alpha 1$-antitrypsin deficiency. Curr Med Chem 2006; 13: 2857-2873.

2. Sandford AJ, Weir TD, Pare PD. Genetic risk factors for chronic obstructive pulmonary disease. Eur Respir $J$ 1997; 10: 1380-1391.

3. Barnes PJ. Genetics and pulmonary medicine. 9. Molecular genetics of chronic obstructive pulmonary disease. Thorax 1999; 54: 245-252.

4. Hingenboam T. Pulmonary hypertension and chronic obstructive pulmonary Disease. A Case for Treatment. Proc Am Thorac Soc 2005; 2: 12-19. 
5. Bhowmik A, Seemungal T, Sapsford R, Wedzicha J. Relation of sputum inflammatory markers to symptoms and lung function changes in COPD exacerbations. Thorax 2000; 55: 114-120.

6. Fujimoto K, Kitaguci Y, Kubo K, Honda K. Clinical analysis of chronic obstructed pulmonary disease phenotypes classified using high-resolution computed tomnography. Respirology 2006; 11: 731-40.

7. Kitaguchi Y, Fujimoto K, Kubo K, Honda T. Characteristics of COPD phenotypes classified according to the findings of HRCT. Respir Med 2006; 100: 1742-52.

8. Filippatos G, Gangopadhyay N, Lalude O, et al. Regulation of apoptosis by vasoactive peptides. Am J Physiol Lung Cell Mol Physiol 2001; 281: 749-761.

9. Popowski K, Sperker B, Kroemer HK, et al. Functional significance of a hereditary adenine insertion variant in the 5'-UTR of the endothelin-1 gene. Pharmacogenetics 2003; 13: 445-451.

10. Tanaka C, Kamide S, Takiuchi, Kawano Y, Miyata T. Evaluation of the Lys198Asn and 134 delA genetic polymorphisms of the endothelin-1 gene. Hypertens Res 2004; 27: 367-371.

11. Sampsonas F, Antonacopoulou A, Spathas D, et al. Positive association between two polymorphic sites (+134insA/delA and G198T) of the endothelin-1 gene and chronic obstructive pulmonary disease. A case control study. Respir Med 2010; 104: 114-120.

12. Kaparianos A, Argyropoulou E, Efremidis G, Flordellis $\mathrm{C}$, Spiropoulos K. Decline in $\mathrm{FEV}_{1}$ related to genetic polymorphisms (+138insA/delA and Lys198Asn) of the endothelin-1 gene in COPD. A pilot study. Eur Rev Med Pharmacol Sci 2010; 14: 705-19.

13. Spiropoulos K, Trakada G, Nikolaou B, et al. Endothelin-1 levels in the pathophysiology of chronic obstructive pulmonary disease. Respir Med 2003; 97: 983-989.

14. Bacakoglu F, Atasever A, Ozhana MH, Gurgun C, Ozkilic H, Guzelant A. Plasma and bronchoalveolar lavage fluid levels of Endothelin-1 in patients with Chronic Obstructive Pulmonary Disease and Pulmonary Hypertension. Respiration 2003; 70: 594-599.

15. Morrison NJ, Abboud RT, Ramadan F, et al. Comparison of single breath carbon monoxide diffusing capacity and pressure-volume curves in detecting emphysema. Am Rev Respir Dis 1989; 139: 1179-1187.
16. Quanjer PH, Tammeling GJ, Cotes JE, Pedersen OF, Peslin R, Yernault JC: Lung volumes and forced ventilatory flows. Report Working Party Standardization of Lung Function Tests, European Community for Steel and Coal. Official Statement of the European Respiratory Society. Eur Respir J 1993, Suppl 16: 5-4.

17. American Thoracic Society. Standardization of spirometry. Am J Respir Crit Care Med 1995; 152: 1107-1136.

18. Silverman EK, Palmer LJ. Case-control associations studies for the genetics of complex respiratory disorders. Am J Respir Cell Mol Biol 2000; 22: 645-648.

19. Ishii T, Matsuse T, Teramoto S, et al. Neither IL-1b, IL1 receptor antagonist, nor TNF-a polymorphisms are associated with susceptibility to COPD. Respir Med 2000; 94: 847-851.

20. Keatings VM, Cave SJ, Henry MJ, et al. A polymorphism in the tumor necrosis factor-a gene promoter region may predispose to a poor prognosis in COPD. Chest 2000; 118: 971-975.

21. Hoidal JR. Genetics of COPD: present and future. Eur Respir J 2001; 18: 741-743.

22. Global Initiative for Chronic Obstructive Lung Disease. Global Strategy for Diagnosis, Management, and Prevention of COPD. www.goldcopd.com/ Guidelineitem.asp?11 = 2\&12 = 1\&intId = 989 Date last updated: December 2007.

23. Widzicha JA. The heterogeneity of chronic obstructive pulmonary disease. Thorax 2000; 55: 631-632.

24. Baldi S, Miniati M, Bellina CR, et al. Relationship between extent of pulmonary emphysema by high-resolution computer tomography and lung elastic recoil in patients with chronic obstructive pulmonary disease. $\mathrm{Am} J$ Respir Crit Care Med 2001; 164: 585-589.

25. Hizawa N, Makita H, Nasuhara Y, et al and the Hokkaido COPD cohort study group. Functional single nucleotide polymorphisms of the ccl5 gene and nonemphysematous phenotype in COPD patients. Eur Respir $J$ 2008; 32: 372-378.

26. Barnes PJ. Small airways in COPD. $N$ Engl J Med 2004; 350: 2635-2637.

27. Hogg JC, Chu F, Utokaparch S, et al. The nature of small airway obstruction in Chronic Obstructive Pulmonary Disease. N Engl J Med 2004; 350: 2645-53.

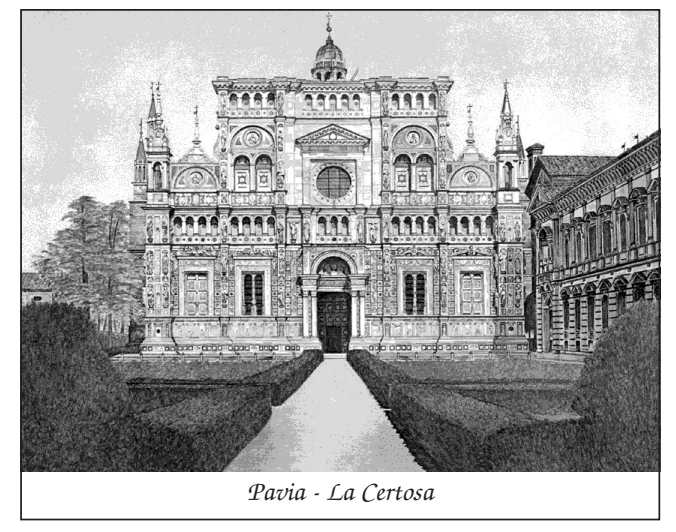

